\title{
Alergia às Proteínas do Leite de Vaca: Uma Nova Era
}

Cow's Milk Allergy: A New Era

Filipe Benito Garcia, Inês Mota, Susana Piedade, Mário Morais-Almeida

\section{RESUMO}

A alergia às proteínas do leite de vaca apresenta uma prevalência, gravidade e persistência crescentes. A dieta de evicção é difícil de cumprir e as reações adversas potencialmente graves associadas à ingestão acidental do alimento são frequentes. Discute-se o caso clínico de uma criança de seis anos com história pessoal de alergia às proteínas do leite de vaca desde os três meses de vida, com vários episódios de anafilaxia por ingestão acidental de leite de vaca. Aos quatro anos foi submetida, com sucesso, a protocolo de indução de tolerância ao leite de vaca, permitindo-Ihe atualmente uma dieta livre. Esta estratégia terapêutica mostra-se revolucionária por permitir modificar a história natural da alergia às proteínas do leite de vaca grave e persistente, com impacto muito positivo na qualidade de vida dos doentes e da sua família.

PALAVRAS-CHAVE: Criança; Hipersensibilidade a Leite; Proteínas do Leite/efeitos adversos

\section{ABSTRACT}

Allergy to cow's milk proteins is common, serious and of growing persistence. A milk-free diet is difficult to comply with and the potentially serious adverse reactions associated with accidentally ingesting the product are frequent. We discuss the clinical case of a six-year-old child with a personal history of allergies to cow's milk proteins since three months old, with various episodes of anaphylaxis caused by the accidental ingestion of cow's milk. At the age of four the child was successfully submitted to cow's milk tolerance induction methods, allowing the child now to have a free diet. This therapeutic strategy is revolutionary as it allows the natural history of serious and persistent allergy to cow's milk to be modified, with a very positive impact on the quality of life of the patients and their families.

KEYWORDS: Child; Milk Hypersensitivity; Milk Proteins/adverse effects 


\section{INTRODUÇÃO}

Nas últimas décadas, a alergia alimentar tem assumido uma prevalência e gravidade crescentes, ${ }^{1}$ estimando-se que atinja atualmente mais de $5 \%$ das crianças em idade pré-escolar. ${ }^{2}$ A apresentação clínica é variável, desde manifestações mucocutâneas, respiratórias, gastrointestinais até à anafilaxia, uma reação potencialmente fatal que pode ocorrer mesmo com a ingestão de doses mínimas do alergénio, frequentemente na forma oculta. ${ }^{1}$

A alergia às proteínas do leite de vaca (APLV) é a alergia alimentar mais frequente em idade pediátrica, ${ }^{2}$ afetando menos de $1 \%$ das crianças nos primeiros dois anos de vida. ${ }^{3}$ Apesar da maioria das crianças resolver espontaneamente a APLV, dados recentes mostram que os quadros clínicos tendem a ser mais persistentes, com taxas de resolução de apenas 19, 42, 64 e 79\%, em crianças com idades de 4, 8, 12 e 16 anos, respetivamente. ${ }^{4}$

A abordagem clássica da alergia alimentar passa pela evicção rigorosa do alimento e tratamento sintomático dos episódios acidentais. Os casos de APLV persistente e grave apresentam um prognóstico menos favorável pela elevada probabilidade da ocorrência de reações adversas por exposição ao alergénio, nomeadamente oculto. ${ }^{4}$

A indução de tolerância oral (ITO) surgiu recentemente como alternativa terapêutica inovadora na abordagem da APLV IgE-mediada persistente e grave, independentemente do grau de sensibilização, ${ }^{4}$ tendo sido o nosso grupo pioneiro na sua aplicação em Portugal, com sucesso, desde há mais de uma década. ${ }^{5-7}$

\section{CASO CLÍNICO}

Criança do sexo feminino, de 6 anos de idade, com antecedentes familiares de doença alérgica (pai e avó paterna) e pessoais de eczema atópico e asma. Fez aleitamento materno exclusivo até aos 4 meses, altura em que introduziu fórmula láctea adaptada (FA). Ao quinto dia de alimentação com FA, meia hora após a primeira ingestão de papa láctea, ocorreu episódio de urticária peribucal e vómito alimentar, com resolução espontânea em 15 minutos. Durante a segunda ingestão de papa láctea, aparecimento, em menos de 5 minutos, de urticária generalizada, angioedema das extremidades e vómitos alimentares. Foi contactado o pediatra assistente que deu indicação para terapêutica com anti-histamínico e corticoide oral, com resolução espontânea em menos de 2 horas.

Em consulta de Pediatria, por suspeita de APLV,é pedido doseamento sérico de IgE específica para leite de vaca (LV) que se revelou positivo (1,2 KU/L), ficando com indicação para evicção de PLV, sendo substituída a FA por uma fórmula extensamente hidrolisada (FEH).

Entre os 4 meses e os 2 anos de idade houve referência a vários episódios de urticária de contacto por exposição a lacticínios.

Aos 2 anos iniciou frequência de infantário e, 3 meses depois, teve episódio de anafilaxia (sintomas de rinite, dificuldade respiratória e vómitos alimentares) 2 minutos após ingestão acidental de pudim feito com LV, que resolveu 2 horas após administração de broncodilatador inalado.

Nessa sequência, é enviada a consulta de Imunoalergologia deste hospital, no âmbito da qual são efetuados testes cutâneos por picada com extratos comerciais (laboratórios Bial-Aristegui, Portugal) positivos para LV (5 mm de pápula média), caseína ( $8 \mathrm{~mm}$ ), $\alpha$-lactoalbumina (9 mm) e $\beta$-lactoglobulina (13 mm), assim como avaliação analítica sérica que revelou lgE total $487 \mathrm{UI} / \mathrm{mL}$ e IgE específicas (ImmunoCAP ${ }^{\circledR}$, Phadia, Uppsala, Suécia) positivas para LV (>100 KU/L), caseína (>100 KU/L), $\alpha$-lactoalbumina $(38,0 \mathrm{KU} / \mathrm{L})$ e $\beta$-lactoglobulina $(2,1$ $\mathrm{KU} / \mathrm{L})$. Confirmado o diagnóstico clínico de APLV, sem indicação no momento para realização de prova de provocação oral, foi indicada a manutenção de evicção rigorosa de PLV e prescrita terapêutica de SOS para episódios de reação alérgica acidental, incluindo anti-histamínico não sedativo e corticoide oral, broncodilatador tópico inalado de curta ação e, em caso de anafilaxia, dispositivo para autoadministração de adrenalina na dose de 0,15 mg. Pelos antecedentes de asma e eczema atópico foi medicada com fluticasona inalada 125 mg duas vezes por dia, emoliente corporal diário e corticoide tópico em SOS.

Aos dois anos e 8 meses, 10 minutos após ingestão acidental de pequena quantidade de LV, contida em concentrado de sumo de laranja, desenvolveu novo episódio de anafilaxia (sintomas de rinite e dificuldade respiratória, vómitos alimentares e angioedema palpebral), que resolveu 3 minutos após administração de adrenalina intramuscular, anti-histamínico não sedativo e corticoide oral.

Aos quatro anos e 6 meses repetiu análises de que destacamos, IgE específica para LV 75,1 KU/L, caseína 83,6 $\mathrm{KU} / \mathrm{L}, \boldsymbol{\alpha}$-lactoalbumina $12,5 \mathrm{KU} / \mathrm{L}$ e $\beta$-lactoglobulina 14,5 KU/L. Foram também repetidos testes cutâneos por picada com extratos comerciais, mantendo-se positivos para LV (9,5 mm), caseína (11 mm), $\alpha$-lactoalbumina (12,5 mm) e $\beta$-lactoglobulina (14,5 mm).

Perante este quadro clínico de episódios recorrentes de anafilaxia por ingestão inadvertida de PLV, com mantida e significativa sensibilização na avaliação in vivo e in vitro, após explicação detalhada dos riscos e das vantagens do procedimento, incluindo à criança, foi proposto à família iniciar protocolo de indução de tolerância oral específica às PLV, o qual foi aceite.

Durante o protocolo (detalhado na Tabela 1), garantindo-se o acesso permanente à equipa de saúde, verificaram-se reações alérgicas ligeiras (mucocutâneas e/ou respiratórias e/ou gastrointestinais), tanto no domicílio como em meio hospitalar, todas elas com resolução após terapêuti- 
TABELA 1. Protocolo de indução de tolerância oral específica às proteínas do leite de vaca.

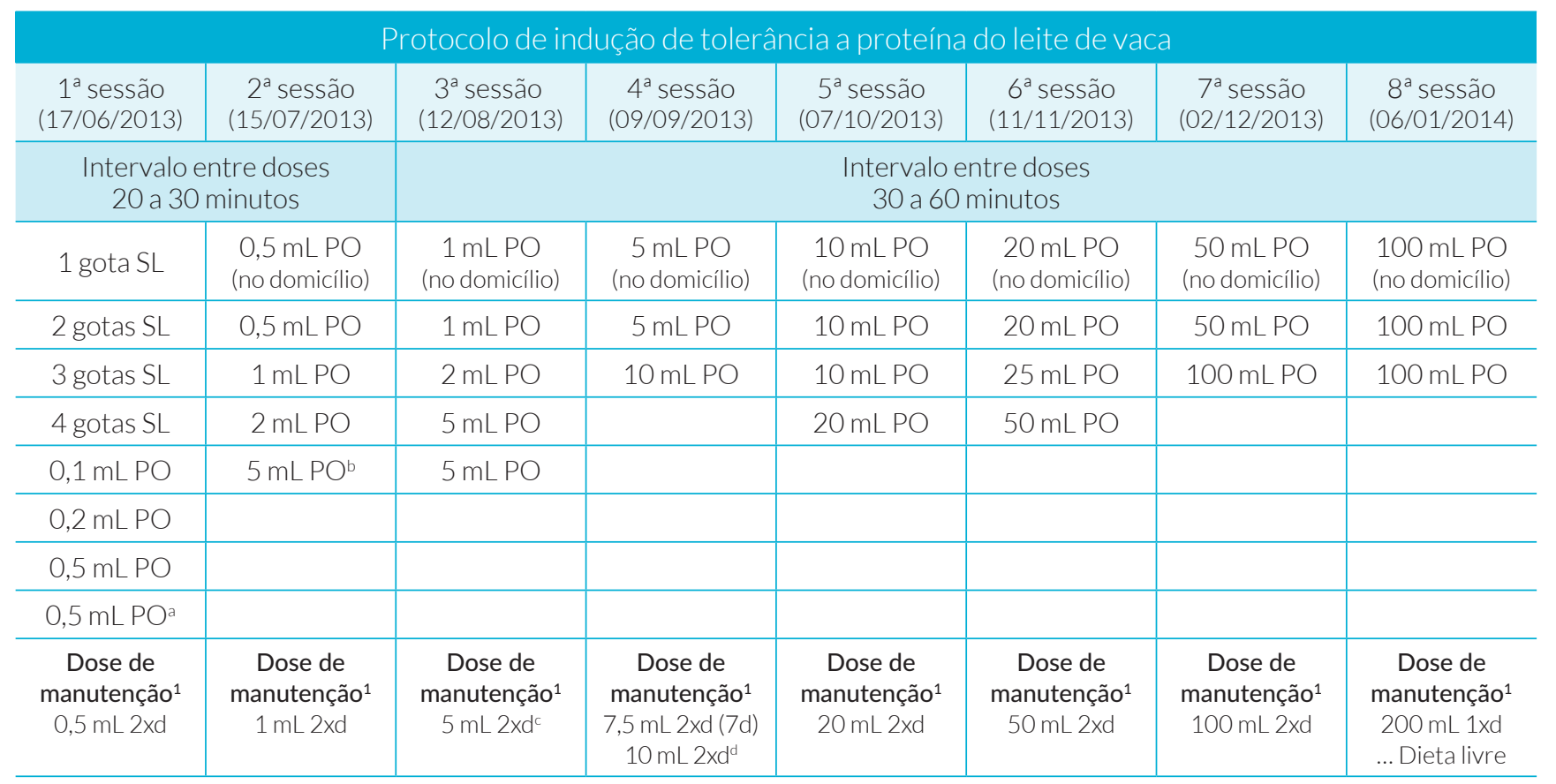

PO: Administração via oral; SL: Sublingual; d: Dia

${ }^{1}$ As doses de manutenção foram cumpridas no domicílio

a 10 minutos depois: Pápulas eritematosas no tronco, membro superior esquerdo e região peri-umbilical que resolveram com anti-histamínico oral (cetirizina $5 \mathrm{~mL}$ )

b 15 minutos depois: Dor abdominal, tosse, eritema da face e vómito que resolveram com anti-histamínico e corticoide orais (cetirizina 5 mL e betametasona $5 \mathrm{~mL}$ )

2 dias após ter iniciado a dose de $5 \mathrm{~mL} 2$ vezes por dia, 30 minutos após a $2^{\text {a }}$ toma, iniciou quadro de dispneia que evoluiu progressivamente para urticária que resolveram com broncodilatador inalado de curta ação e anti-histamínico oral. Reduziu dose de manutenção para 2,5 mL 1 vez por dia durante um dia, em seguida passou a $2,5 \mathrm{~mL} 2$ vezes por dia durante 7 dias e depois aumentou diariamente 0,5 mL por dose até perfazer a dose de $5 \mathrm{~mL} 2$ vezes por dia

dIngeriu 7,5 mL 2 vezes por dia durante 7 dias e depois, aumentou progressivamente 0,5 $\mathrm{mL}$ por dia até perfazer a dose de $10 \mathrm{~mL}$ 2 vezes por dia

ca oral/inalatória, justificando ajustes de doses e do número de sessões. Cumpriu um total de 8 sessões, em regime de hospital de dia, num período de cerca de 7 meses.

No final do protocolo foi dada indicação para ser mantida a ingestão diária da dose de manutenção de $200 \mathrm{~mL}$ por dia e dieta com introdução progressiva de alimentos lácteos. Recomendou-se evicção da prática de exercício físico intenso 2 a 3 horas após ingestão de PLV e o contacto à equipa médica em caso de intercorrência infeciosa ou agudização da doença alérgica.

Aos seis anos e 10 meses, já a frequentar a escolaridade, encontra-se a tolerar uma dieta livre para lacticínios, com grande satisfação da criança e dos seus conviventes. Tem programado acompanhamento regular na consulta de Imunoalergologia.

\section{DISCUSSÃO}

As reações adversas a alimentos, podem ser de causa alérgica, mediadas por mecanismos imunológicos (alergia alimentar IgE ou não IgE-mediada), ou devidas a outras formas de hipersensibilidade/intolerância. As formas IgE-mediadas constituem mais de metade dos casos de APLV, apresentando-se habitualmente por sintomatologia imediata, pouco tempo após a ingestão. ${ }^{1}$

Dos doentes com APLV, até 50\% desenvolvem alergias a outros alimentos, ${ }^{9,10}$ até 40\% apresentam asma, 20\% eczema atópico e até 30\% rinoconjuntivite. ${ }^{9}$ No presente caso clínico, a doente tinha história de eczema atópico e asma.

A abordagem terapêutica clássica, nomeadamente a dieta de evicção e o tratamento de episódios acidentais, tem-se revelado insuficiente e associada a um elevado risco de reação alérgica potencialmente grave por ingestão inadvertida de LV, um alergénio alimentar altamente disseminado nos alimentos processados. ${ }^{11}$

Num cenário de fatores não controláveis e potenciadores da ocorrência de reações adversas, com elevados índices de gravidade, como documentado neste caso clínico, tendência para duração mais prolongada, e o forte impacto na qualidade de vida dos doentes e suas famílias, surgiu a ITO especialmente para o leite de vaca.

$\mathrm{Na}$ atualidade, as metodologias de ITO na alergia alimentar são ainda muito variáveis, nomeadamente no que respeita à duração da fase de indução ou de iniciação. Nos protocolos convencionais a fase de indução 
pode durar até vários meses, com aumentos de dose diários ou a intervalos de poucas semanas. Nos protocolos ultra-rush, os aumentos de dose fazem-se a cada 20 minutos até poucas horas. Existem ainda os protocolos mistos que se iniciam com uma fase rush, seguida de uma abordagem convencional mais lenta. ${ }^{5}$

Tal como acontece com outras formas de imunoterapia, podem ocorrer reações adversas locais ou sistémicas, de ligeiras a muito graves, sendo estas possíveis em qualquer fase do tratamento, mas sendo muito mais frequentes na fase inicial da indução. ${ }^{6}$

Perante as várias limitações dos protocolos existentes, de entre as quais se destaca a duração prolongada dos protocolos convencionais ${ }^{12}$ e o elevado número de reações adversas dos protocolos rush, ${ }^{13}$ o Centro de Alergia ${ }^{6}$ desenvolveu um protocolo misto, sublingual e oral, utilizando como extrato alergénico LV puro em natureza. As doses iniciais sublinguais (contacto com a mucosa oral durante 2 a 3 minutos, eliminando posteriormente o alergénio), são seguidas da ingestão oral de doses progressivamente crescentes de LV, atingindo a dose alvo de 200 mL/dia, num intervalo médio de 20 semanas, sendo esta uma dose consensualmente aceite como critério de sucesso da intervenção. Este protocolo tem revelado excelente eficácia e segurança, mesmo em quadros com clínica de anafilaxia grave, independentemente dos níveis das IgEs específicas para as PLV.

São conhecidos vários fatores associados a risco aumentado de reação alérgica para doses de alergénio alimentar previamente toleradas, nomeadamente o exercício físico intenso, o jejum, infeções ou estados febris, o período menstrual e a doença alérgica mal controlada. ${ }^{14}$ Deste modo, doentes com história de anafilaxia, como no caso apresentado, devem continuar a ser portadores do dispositivo para autoadministração de adrenalina, mesmo após conclusão do protocolo e deverá ser garantido o controlo das doenças alérgicas coexistentes durante e após a sua conclusão. 6,14

Nos últimos anos, têm-se multiplicado as publicações sobre esta abordagem nas suas diferentes modalidades, existindo já estudos controlados que confirmam as elevadas taxas de sucesso, bem como a persistência do efeito após vários anos de tratamento, geralmente dependente da exposição mantida ao alergénio alimentar. ${ }^{15}$

Em conclusão, esta estratégia terapêutica constitui a única possibilidade de interferir na história natural da doença alérgica, conferindo proteção relativamente à ingestão inadvertida de LV, especialmente na forma de alergénio oculto, o que permite uma melhoria significativa da qualidade de vida, reduzindo o tremendo impacto desta patologia nos doentes e na família implicada. Realçamos, no entanto, que deverá ser criteriosamente utilizada, sempre com a supervisão de especialistas experientes, em centros com a necessária diferenciação, garantindo a segurança e a eficácia da intervenção.

CONFLITOS DE INTERESSE: Os autores declaram a inexistência de conflitos de interesse na realização do presente trabalho.

FONTES DE FINANCIAMENTO: Não existiram fontes externas de financiamento para a realização deste artigo.

CONFIDENCIALIDADE DOS DADOS: Os autores declaram ter seguido os protocolos do seu centro de trabatho acerca da publicação dos dados de doentes.

\section{REFERÊNCIAS}

1. Boyce JA, Assa’ad A, Burks AW, Jones SM, Sampson HA, Wood RA, et al. Guidelines for the diagnosis and management of food allergy in the United States: Report of the NIAID-Sponsored Expert Panel. J Allergy Clin Immunol. 2010;126:S1-S58.

2. Nwaru BI, Hickstein L, Panesar SS, Robert G, Muraro A; EAACI Food Allergy and Anaphylaxis Guidelines Group, et al. Prevalence of common food allergies in Europe: a systematic review and meta-analysis. Allergy. 2014;69:992-1007.

3. Schoemaker AA, Sprikkelman AB, Grimshaw KE, Roberts G, Grabenhenrich L, Rosenfield L, et al. Incidence and natural history of challenge-proven cow's milk allergy in European children - EuroPrevall birth cohort. Allergy. 2015;70:963-72.

4. Skripak JM, Matsui EC, Mudd K, Wood RA. The natural history of IgE-mediated cow's milk allergy. J Allergy Clin Immunol. 2007;120:1172-7.

5. Morais-Almeida M, Piedade S, Couto M, Sampaio G, Santa- Marta C, Gaspar A. Inovação na indução de tolerância oral específica em crianças com anafilaxia às proteínas do leite de vaca. Rev Port Imunoalergol. 2011;19:161-9.

6. Piedade S, Morais-Almeida M. Indução de tolerância em alergia alimentar. In: Castro FF, Galvão CE, editores. Imunoterapia. $1^{a}$ ed. São Paulo: Editora Manole Lda; 2011. p.125-47.

7. Couto M, Gaspar A, Santa-Marta C, Morais-Almeida M. 8 years follow-up after rush specific oral tolerance induction to cow's milk proteins. J Med Cases. 2012;3:313.

8. Johansson SG, Hourihane JO, Bousquet J, Bruijnzeel-Koomen C, Dreborg S, Haahtela T, et al. A revised nomenclature for allergy - An EAACI position statement from the EAACI nomenclature task force. Allergy. 2001;56:813-24.

9. Santos A, Dias A, Pinheiro JA. Predictive factors for the persistence of cow's milk allergy. Pediatr Allergy Immunol. 2010;21:1127-34.

10. Host A. Clinical course of cow's milk protein allergy and intolerance. Pediatr Allergy Immunol. 1998;9:48-52.

11. Martorell-Aragonés A, Echeverría-Zudaire L, Alonso-Lebrero E, Boné-Calvo J, Martín-Muñoz MF, Nevot-Falcó S, et al. Position document: IgE-mediated cow's milk allergy. Allergol Immunopathol (Madr). 2015;43:507-26.

12. Meglio P, Bartone E, Plantamura M, Arabito E, Giampietro PG. A protocol for oral desensitization in children with IgE-mediated cow's milk allergy. Allergy. 2004;59:980-7.

13. Martorell-Aragonés A, Félix Toledo R, Cerdá Mir JC, Martorell Calatayud A. Oral rush desensitization to cow milk. Following of desensitized patients during three years. Allergol Immunopathol. 2007;35:174-6.

14. Couto M, Gaspar A, Santa-Marta C, Morais-Almeida M. Cow's milk dependent exercise-induced urticaria after oral tolerance induction in an adolescent. Allergol Immunopathol (Madr). 2012;40:67-8.

15. Yeung JP, Kloda LA, McDevitt J, Ben-Shoshan M, Alizadehfar R. Oral immunotherapy for milk allergy (review). Cochrane Database Syst Rev. 2012: CD009542. 